\title{
Misrecognition of need: Women's experiences of and explanations for undergoing cesarean delivery
}

\author{
Kristin P. Tully, Ph.D. [Postdoctoral Fellow] and \\ Carolina Consortium on Human Development at the University of North Carolina at Chapel Hill. \\ She is an Associate of the Carolina Global Breastfeeding Institute, University of North Carolina at \\ Chapel Hill
}

\author{
Helen L. Ball, Ph.D. [Professor] \\ Department of Anthropology, and Fellow of the Wolfson Research Institute, Durham University, \\ Durham, UK
}

\begin{abstract}
International rates of operative delivery are consistently higher than the World Health Organization determined is appropriate. This suggests that factors other than clinical indications contribute to cesarean section. Data presented here are from interviews with 115 mothers on the postnatal ward of a hospital in Northeast England during February 2006 to March 2009 after the women underwent either unscheduled or scheduled cesarean childbirth. Using thematic content analysis, we found women's accounts of their experiences largely portrayed cesarean section as everything that they had wanted to avoid, but necessary given their situations. Contrary to popular suggestion, the data did not indicate impersonalized medical practice, or that cesareans were being performed 'on request.' The categorization of cesareans into 'emergency' and 'elective' did not reflect maternal experiences. Rather, many unscheduled cesareans were conducted without indications of fetal distress and most scheduled cesareans were not booked because of 'choice.' The authoritative knowledge that influenced maternal perceptions of the need to undergo operative delivery included moving forward from 'prolonged' labor and scheduling cesarean as a prophylactic to avoid anticipated psychological or physical harm. In spontaneously defending themselves against stigma from the 'too posh to push' label that is currently common in the media, women portrayed debate on the appropriateness of cesarean childbirth as a social critique instead of a health issue. The findings suggest the 'need' for some cesareans is due to misrecognition of indications by all involved. The factors underlying many cesareans may actually be modifiable, but informed choice and healthful outcomes are impeded by lack of awareness regarding the benefits of labor on the fetal transition to extrauterine life, the maternal desire for predictability in their parturition and recovery experiences, and possibly lack of sufficient experience for providers in a variety of vaginal delivery scenarios (non-progressive labor, breech presentation, and/or after previous cesarean).
\end{abstract}

\footnotetext{
(C) 2013 Elsevier Ltd. All rights reserved.

Correspondence Kristin P. Tully, Postdoctoral Fellow, Center for Developmental Science, 100 East Franklin Street, Suite 200, Campus Box 8115, Chapel Hill, North Carolina, 27599 (Kristin.Tully@unc.edu).

Kristin and Helen are also members of the Durham University Parent-Infant Sleep Laboratory, Queen's Campus, Stockton-on-Tees, UK.

Publisher's Disclaimer: This is a PDF file of an unedited manuscript that has been accepted for publication. As a service to our customers we are providing this early version of the manuscript. The manuscript will undergo copyediting, typesetting, and review of the resulting proof before it is published in its final citable form. Please note that during the production process errors may be discovered which could affect the content, and all legal disclaimers that apply to the journal pertain.
} 


\section{Keywords}

UK; decision-making; cesarean section; authoritative knowledge

\section{Introduction}

The incidence of primary cesarean section is consistently higher (Betrán et al., 2007; Declercq et al., 2011; Menacker \& Hamilton, 2010) than the 10-15\% calculated as appropriate (WHO, 2009), suggesting factors other than clinical indications influence the deliveries (Bragg et al., 2010; Stavrou et al., 2011). Torloni et al. (2011) summarize that mechanisms underlying global disparities in birth mode, and the reasons for the nearly universal trend of increasing cesarean section rates, are unclear. Medically unnecessary cesarean section is a public health concern because of the excess morbidity compared to vaginal childbirth, such as greater child respiratory infections (Merenstein et al., 2011), placental complications in subsequent pregnancies (Silver, 2010; Solheim et al., 2011), and greater maternal mortality (Clark et al., 2008; Kamilya et al., 2010). Women of all ages are increasingly undergoing operative delivery and the proportion among older mothers is especially high (Hamilton et al., 2010). The increasing rates and associated risks raise questions about why women acquiesce to the 'need' for operative delivery, and where the 'need' is located: with the mothers, the infants, or the hospital staff? Are women fully informed about the consequences of cesarean section and do they understand their options? This paper examines mother's experiences of operative delivery in a United Kingdom hospital, and explores how women understand and rationalize their birth experiences.

One of the most prevalent indications for primary cesarean section is 'non-progressive' labor (Zhang et al., 2010), despite lack of association between relatively prolonged labor without indications of fetal distress and detrimental health outcomes (Mancuso \& Rouse, 2008). Intervention in such cases may be a consequence of misunderstanding physiology and the perception of Western, technological medicine as offering control over 'unpredictable' natural processes. Ingrained biases arising from discriminatory terminology such as 'failed' labor may contribute to the ways in which both health professionals and women approach childbirth (Davis-Floyd, 1993). Martin (1991) explains that medicine is commonly considered distinct from culture, but medical culture is actually a powerful system of socialization. These influences, rather than lack of physician training or overzealous use of interventions, may potentially underlie the high proportion of cesarean deliveries conducted without medical indication (see Menacker et al., 2006). Within this technology-centered and biologically reductionist framework, cesarean is a logical intervention when labor trajectories deviate from 'normal' and therefore safe ranges. The use of the term 'emergency' to describe all unscheduled cesareans may mask the uncertainty of actual situations and various strategies available.

There are currently many classification systems for cesarean section, which are based on indications (why), urgency (when), characteristics of the mothers (who), and other aspects of the deliveries (where, how, by whom, and combinations) (Torloni et al., 2011). The term 'emergency' cesarean is frightening to women (Redshaw \& Hockley, 2010) and 'elective' may also be misleading. In medical terminology, elective means that an operation is scheduled, whereas in lay terms it conveys choice and possibly demand. Publications increasingly address cesarean delivery "on maternal request" (CDMR) in an effort to identify the driver of rising cesarean rates and therefore effectively target interventions. However, 'request' may be an inappropriate term because fear of childbirth, existing medical complications, and anxiety regarding health outcomes are commonly reported in this group (i.e., Romero et al., 2011; Wiklund et al., 2007). The impression that CDMR is 
common, as evidenced in the UK and US media (i.e., Alleyne, 2011; Cheng, 2011; De Angelis, 2011; Lawrence, 2011; Song et al., 2004), is not supported by the research/clinical literature (i.e., Declercq et al., 2006; Thomas \& Paranjothy, 2001).

Why mothers 'go along with' technological childbirth interventions such as cesarean section is debated (see Kitzinger et al., 2006; Klein et al., 2006). Fear of the unknown, pain, losing control, and/or concern for offspring wellbeing are key factors (Fisher et al., 2006). Uterine rupture is also of vital concern, as the consequences can involve significant maternal morbidity and perinatal mortality (Ronel et al., 2011). The desire, and cultural pressure, to protect offspring in medical crises and 'emergencies' constrain decision-making. Maternal autonomy in childbirth is also complicated by the diverse values of the parties involved and the meaning of the various outcomes to individuals' lives (Kukla et al., 2009). Kingdon et al. (2009) suggest choice is an inappropriate concept for childbirth because maternal autonomy is also limited by the dynamic nature of individual circumstance and available care. Another reason that cesarean section may be perceived as the safest course of action is structural constraints; physicians trained in vaginal delivery with complications such as breech positioning are uncommon (e.g. Hannah et al., 2000). This is therefore a complex issue because if maternity units do not require staff who meet such descriptions, then vaginal birth may be less likely to be realized and riskier than cesarean section. However, whether expectant mothers are aware of this more nuanced distinction of childbirth in context is unknown. Karlström et al. (2011a) found that women who had a 'preference' for and were delivered by cesarean felt more dissatisfied with their care and birth experience than others. Further, the reported worst part of mothers' planned cesarean experiences was the process of deciding on the delivery mode.

Instead of isolated and individual decision-making, attention is increasingly centered on childbirth influences within culturally constructed knowledge (Béhague, 2002; Bryant et al., 2007; Munro et al., 2009; Wendland, 2007; Wittmann-Price et al., 2009), especially about the 'ease' and safety of cesarean section versus vaginal delivery (Gamble et al., 2007; Walker al., 2004; Weaver et al., 2007). 'Preference' for cesarean section is predicted by maternal beliefs about childbirth, including the degree of confidence they have in realizing vaginal delivery (Stoll et al., 2009) and whether they consider birth as a natural event (Haines et al., 2011). The current emphasis on maternal autonomy evidenced by the recent UK policy that women can 'choose' to undergo a cesarean section in the absence of current medical indication (see NICE, 2011), may distract from the importance of women's reproductive histories and the factors that contribute to their understandings of appropriate childbirth processes and outcomes. Few to no 'requests' for cesarean section are documented as occurring in the absence of, what women consider, clinical or psychological indications (Karlström et al., 2011b, Weaver et al., 2007).

Convenience of both individual mothers and their physicians is often cited as a substantial influence of cesarean section delivery. The "too posh to push" mantra suggests that women are freely choosing to undergo cesarean section. Additionally, due to the discrepancy between intended and actual birth modes in their sample, Potter et al. (2008) suggest that the hospital staff must have embellished medical conditions in order to persuade the families to undergo the more institutionally convenient cesarean section delivery. These researchers dismiss the idea that the physicians were uncertain of diagnosing complications due to the fact that they were practicing in urban locations in which they should have sufficient experience. Perhaps the context in which medical professionals are educated and subsequently practice, combined with litigious settings in which the appropriate role of a doctor is deemed as interventionist, is relevant in explaining this difference? 
Recent research strives for a holistic understanding of childbirth experiences, based on women's perceptions of risk (Sharma et al., 2011), the myriad of meanings underlying notions of 'control' (Namey \& Lyerly, 2010), pain (Declercq et al., 2008), previous delivery outcomes (David et al., 2010; Kaimal \& Kuppermann, 2010; Pang et al., 2008), race (Getahun et al., 2009; Rosenthal \& Lobel, 2011; Selo-Ojeme et al., 2008), medical record information (Wibe et al., 2011), midwifery practices (Danerek et al., 2011), and community factors (Leone et al., 2008). These influences are increasingly viewed as interacting, and are replacing the antagonistic view of defensive medicine that dominated earlier literature (Bassett et al., 2000).

The concept of authoritative knowledge as used in medical anthropology (Jordan, 1993; 1997) unifies these multiple domains known to affect cesarean section delivery rates. This framework suggests the information that 'counts' in childbirth events is mutually constructed among families, health care providers, and the wider public because it explains "the state of the world better for the purposes at hand" than other perspectives (Jordan, 1993, p. 152). Authoritative knowledge can be easily misconstrued as meaning the information held by those in hierarchical positions. However, Jordan explicitly states that this is not what she means (1993, p. 53). Authoritative knowledge is the story that 'makes sense' and therefore influences behavior.

A tenet of authoritative knowledge is that some kinds of indications become "discredited and devalued, while others become socially sanctioned, consequential, even official" (Jordan, 1993, p. 150). Obstetrics is a unique medical specialty because it does not primarily deal with pathology. Davis-Floyd (1993) suggests that most obstetricians are sued because of the under-use of technology, not its overuse. Doctors are trained "to do something" (Eisenberg, 1988, p. 488). Davis-Floyd (1994) describes a cycle of technology-centered care that begins in medical training and is reinforced through example. Alongside the benefits of Western biomedicine is the loss of other forms of knowledge (Ginsburg \& Rapp, 1991). The main problem that then arises, according to Davis-Floyd and St. John (1998), is medical training often decontextualizes childbirth pathologies from the circumstances in which (and people for whom) they are experienced.

The purpose of this paper is therefore to document the circumstances in which cesarean section was deemed to be appropriate in one UK hospital through the eyes of the women and their partners experiencing the operative delivery of their infant. We explore whether women perceived their childbirth choices as constrained, and if so, how, and contemplate the question "When does a cesarean section become "necessary'?"

\section{Methods}

Semi-structured, open-ended interview data were obtained at a National Health Service (NHS) hospital in Northeast England with two groups of women who experienced cesarean section delivery. During the study this tertiary-level hospital hosted approximately 5,400 births per year; the cesarean section rate was $22 \%$. This figure was consistent with childbirth in England (23\% cesarean) at that time (Bolling et al., 2007).

Phase 1 was conducted from February to April 2006 and comprised participants who underwent either an unscheduled $(n=48)$ or scheduled $(n=27)$ cesarean section delivery. Phase 2 was conducted from January to December 2007 and October 2008 and March 2009 and involved women who experienced scheduled, non-labor cesarean section delivery $(n=40)$. The interview schedule relevant to this analysis was identical in both research phases. Prior to commencing research, approval was obtained from the authors' university, local healthcare authorities, and the NHS ethical review board. Health care professionals 
were not interviewed because the research was conducted as part of the first author's doctoral study, which meant limited funding and time.

Inclusion criteria for both phases specified that mothers must have been at least 18 years of age at the time of enrollment, in good health, fluent in verbal and written English, and have experienced cesarean childbirth. Informed consent was obtained from participants for both phases of the research. Enrolled participants were allocated numerical codes to protect anonymity. The first author, who was not hospital staff, conducted the face-to-face interviews with mothers. Interviews were completed on the postpartum ward during the period between the day after delivery and discharge while no medical professionals were present. Women's partners were permitted to attend the interview, and their spontaneously offered comments were noted separately from participant responses. Questions were worded in a non-leading manner to solicit participant understandings, probes were used to elicit full accounts, and the interviewer wrote down participant responses to each question verbatim during the approximately thirty-minute interviews. A small gratuity to participants was provided in the form of gift cards.

\section{Sample}

In Phase 1, 101 women were approached on the postnatal ward and 75 completed the interview ( 15 declined, 5 did not meet inclusion criteria, 5 were not enrolled due to timing conflicts, and 1 woman was withdrawn because she became unwell during the interview). Phase 2 participants were recruited as part of the authors' subsequent study of mother-infant interactions on the postnatal ward (Tully \& Ball, 2012). Participants were mostly white, predominately first time mothers (range 0-6 previous deliveries) and aged between 18 to 41 years. Their infants were predominately healthy singletons and about half of them were female. Sample characteristics are reported in Table 1.

\section{Analysis}

Participant responses were read in their entirety and entered into a matrix format in response to the interview questions for ease of comparison. Initial codes were then used to create thematic categories across all participants (Wilkinson, 2004). Codes derived from research questions, such as "what factors influenced the decision for cesarean section delivery" as well as refinements of the core issues that emerged, such as 'cesarean section as the childbirth mode in order to avoid previous problems,' which the authors identified through an iterative process.

\section{Findings}

The terms 'emergency' and 'elective' cesarean were largely unreflective of maternal perceptions of their experiences. Many unscheduled cesareans were conducted due to nonprogressive labor without indications of fetal distress (16 of 48), and the majority of scheduled cesareans were scheduled to avoid previously encountered physical or psychological harm (43 of 67). Participants generally described their ideal delivery as one that was emotionally fulfilling and vaginal. However, after previously experiencing frightening 'emergency' cesarean section or painful pelvic floor damage, participants wanted to have a "safer" and more predictable experience. Maternal choices were constrained by previous childbirth trauma and awareness of the inevitable and debilitating postpartum pain associated with operative delivery. Vaginal delivery pain was described as intense, relatively brief, and conferring undue stress on the infant compared to the guaranteed, long lasting, but controllable cesarean section pain. Controllable in this sense referred to pain that was anticipated, limited to around the incision, and pharmacologically managed. 
Cesarean section was described as more predictable with regards to the delivery process, but not an easy experience for the mother. Women recounted "horrendous" postpartum pain and expressed the need for a ladder or rope to assist with maneuvering out of their hospital bed. Although the later stages of labor and the birth itself were considered by women to be the most difficult aspects of vaginal delivery, "the hard bit" of cesarean section delivery was the recovery. Commentary on the 'too posh to push' slogan emerged in the forms of reflection on the seriousness of cesarean section as a major surgical procedure and defense against the stigma of "copping out" of "normal" childbirth. The husband of a 28 -year-old first time mother said the headline portrays cesarean section as easier and "maybe you believe that a little too, but it's a major thing. They could do heart surgery in that [operating] theater." Multiple participants said they would have had a vaginal delivery if not for their circumstances, as they were "not too posh to push."

Fewer than half of the study participants underwent the cesarean section due to a current medical condition, including indications of fetal distress or nonvertex fetal positioning (32 of 48 unscheduled and 23 of 67 scheduled cesarean sections), however the label 'maternal request' could be applied to only 1 of 67 scheduled deliveries. Table 2 outlines four cesarean subgroups: unscheduled for a medical condition; unscheduled without a medical condition; scheduled for a medical condition; scheduled without a medical condition. These categories are described in detail below.

\section{Unscheduled cesarean section delivery without a medical condition}

Unscheduled cesarean section delivery was often understood to be the "way forward" in the context of "failed" labor without indications of fetal distress. These women felt relieved (although often also disappointed) once the decision for cesarean section was made, because they were "a bit panicky before that" when childbirth "didn't feel like it was ever going to happen." A 28-year-old first time mother said she had been "open minded to anything I needed" for delivery, but she "didn't think it would come to that" [having a cesarean]. Participants said that labor had stopped, or that the baby "just wasn't coming down." Although these participants had expected "normal labor," most had not ruled out cesarean section.

All mothers described labor prior to their unscheduled cesareans as wasted effort. The experience was "a shame" because it made them feel more drained and they felt that it conferred undue stress on the infant. Ten of the 16 participants who had unscheduled cesarean section delivery without a current medical condition (62.5\%) said that the cesarean section "turned out to be the best" without qualifying their reply. The remainder spontaneously added that it was necessary, given what they knew. Women in this group employed concepts such as exhausting every alternative, risks, and stress in justifying the appropriateness of cesarean section as their delivery mode. The theme was "enough is enough." Those who were unsure if the delivery mode turned out to be the best cited unanticipated outcomes consequential to the cesarean delivery, primarily in the form of infant respiratory problems, maternal mobility constraints, and breastfeeding difficulties.

A husband agreed with his 29-year-old wife's description of the obstetrical consultant as sympathetic to her feelings during a non-progressive labor without indications of fetal distress. He said that the doctor "seemed to care about you as a person, not just a patient." The partner added, "You weren't just another number and he wasn't trying to keep numbers [of operative deliveries] down at all costs. He took you into account as an individual. Thinking back, they gloss over cesarean sections in hospital [prenatal classes.] They are so reluctant to give cesareans because of targets. The 'too posh to push' label is plainly not true...damn media have almost got it a bad name." 
Only one participant who had an unscheduled cesarean mentioned that she felt that the delivery ward conditions affected her labor progress. This 37-year-old first time mother said fetal monitoring distracted her from focusing on the contractions, and summarized that "the circumstances could have contributed to the cesarean...everything played some role in that." Another participant reflected, "I always thought that I was strong, healthy, and could give birth." The labor of this 32-year-old second time mother had been pharmacologically induced, but she did not mention that as a possible contributing factor in her non-progressive labor.

\section{Unscheduled cesarean section delivery for a medical condition}

When there was a current medical problem, women reported that their unscheduled cesarean section deliveries occurred for the outcome of a healthy infant, involving their own suffering for the sake of the baby. A 28-year-old, first time mother recalled, "My baby's heartbeat was dropping, [the cesarean] wasn't planned at all. One minute we were there [in the delivery room], then they had to get her out...had seconds. We didn't have opportunity to discuss it really. I just knew she was seriously distressed. They said [the situation] was life or death and a threat to me as well." Another participant, who was a 19-year-old first time mother, stated, "I had been in labor for 12 hours and then his heart-rate started dropping. I didn't understand much at all...I never thought that this [a cesarean section delivery] would happen." Fourteen of the 32 participants who had an unscheduled cesarean for a medical condition (43.8\%) agreed the cesarean turned out "best" the majority specified that it was their only option, that it was "medically best," or that it was right "for the baby."

When medical indications were not considered to be urgent, some women were uncertain whether the cesarean section was appropriate:

"I was bleeding so I came in and was put on a monitor. The staff weren't happy with the data. They said it was more favorable to have cesarean section than to induce. I had a choice, but was getting vibes from the doctor that it was probably better to go for a section. I was not very prepared because I was expecting to try for normal [vaginal] delivery, so it was bit of a shock. I was quite lucky still...it's probably worse for some women who go through labor for long time and then end up having an emergency cesarean."

36-year-old second time mother.

The timing of one unscheduled cesarean section delivery for breech positioning was striking because it was not due to an imminent medical situation or maternal preference:

"Rather than my waters breaking and her [baby] getting distressed, I had a section. I had come in for [an ultrasound] scan and it was quiet in labor ward so they suggested that I have it then. It was a shock."

32-year-old second time mother.

Four of the 32 women in the unscheduled cesarean for a current medical condition group reported shock at the delivery, with many never having considered it a possibility and reflecting that they skipped over cesareans in prenatal preparations. The women used terms such as danger and death in describing their need for operative delivery. Almost none of the women said that they had felt prepared for the cesarean section, which, in the words of a 25year-old first time mother, was the "worst thing." An effective lack of decision was beneficial for some mothers in that they did not feel guilty about their childbirth outcome, whereas others emphasized their poor outlook on cesarean sections that they retained postpartum. A 32-year-old second time mother said the cesarean was "the one thing I didn't want, and something I still didn't want." 


\section{Scheduled cesarean section delivery without a medical condition}

Advance booking of a cesarean section was influenced by previous maternal experience. A 32-year-old second time mother said the cesarean was best for her because "With my first baby I was stitched inside and out... was a right mess down below. I didn't like that idea [of having vaginal delivery complications again] at all.” Women who scheduled a cesarean section without a medical condition made decisions based on their other childbirth outcomes, focused on the more straightforward nature of operative delivery, and reported lack of confidence in achieving vaginal delivery:

"My blood pressure had gone up so he had to come out that day. I could have a cesarean or induction, but there was only a 50/50 chance [of vaginal delivery] with the induction. I could labor for [up to] 8 hours."

40-year-old third time mother.

"My other child was [delivered via] an emergency cesarean section and they couldn't guarantee vaginal birth [this time]."

27-year-old second time mother.

Although the protocol at the study hospital was to book the appointment for a cesarean section at about 36 weeks gestation, participants usually reported that they decided on having a scheduled cesarean farther in advance to avoid "having to go through what I did last time." For those who previously experienced complicated vaginal delivery or underwent an unscheduled cesarean section after becoming "needlessly exhausted" laboring, scheduled cesarean section provided control (meaning self-determination of the trajectory of events) and ameliorated fear because women could better anticipate the parturition and recovery process:

"I had a traumatic first delivery... a lot of pain. I had forceps [applied during the vaginal delivery], and [I experienced] incontinence [afterwards] and had a superpubic septum. I had to see a physio[therapist] for months [afterwards]. This baby is bigger [despite being delivered] three weeks earlier than the last one, so I think that I made the right decision. I am uncomfortable now, but [the discomfort is] nothing like last time. I think that I will recover faster this time." 37-year-old second time mother.

Mothers reported that time to familiarize oneself with the surgery enabled the steps to "sink in" and this comfort with the situation was enhanced when the operating staff narrated the process during delivery. Scheduled delivery was described as "completely different" and more positive than an unscheduled cesarean, but still frightening. As a 27-year-old first time mother reflected, "I knew in my head it was going to happen, but it's different when you actually do it." A 31-year-old mother who previously had a vaginal delivery said that her cesarean section was the "weirdest thing in the world" and "not an easy option."

The one first time mother who scheduled a cesarean in the absence of a medical condition described personal and medical reasons. The 34-year-old explained, "My cesarean was elective because it's safer. Also [I was worried about] my high blood pressure and age." She felt unprepared for delivery in part due to her parents having "forgotten their childbirth experiences."

\section{Scheduled cesarean section for a current medical indication}

Only 24 of 67 scheduled cesarean section deliveries (35.8\%) were indicated by a medical condition currently affecting the mother, fetus or both. Nonvertex fetal presentation, which was primarily breech positioning, was viewed a firm medical indication for scheduling a cesarean section instead of undergoing vaginal delivery. A few participants who scheduled 
the cesarean section for breech positioning mentioned having been aware of the possibility of prenatally attempting to turn the baby (via an external cephalic version). Two of these three women had unsuccessfully undergone the procedure and recounted that they then "had to opt" for a cesarean section delivery:

"I never thought I'd have a cesarean. I just sort of skipped through that with the [pregnancy] books. I didn't sort of believe it [when found out the baby was breech]. They tried to turn the baby first, but she wouldn't budge. I was pretty shocked to think I would have to opt for a cesarean... everything went fine through pregnancy and then that." 31-year-old first time mother.

Only one participant conveyed an understanding of breech vaginal delivery being feasible. This woman described cesarean sections as "a last method thing." The 29-year-old second time mother said that her family and friends tried to persuade her to book a cesarean because they considered it easier and safer delivery in the context of suboptimal fetal positioning. Additionally, the first author witnessed an exchange at the study location during which an expectant woman was told that if her breech baby changed position before the scheduled cesarean section delivery, it would be conducted anyway since everyone was planning on it.

\section{Discussion}

According to participant accounts, over half of the decisions for a cesarean section occurred in the absence of a current medical condition. The circumstances that 'counted' towards these decisions for a cesarean section were influential regardless of the indications' physiological "truth value" (Jordan, 1993, p. 149). Unscheduled cesarean was often conducted without indications of fetal distress because it seemed "the way forward" from "failed" labor. Although the duration of women's 'prolonged' labor could have ranged widely, indication for and conduct of many unscheduled cesarean sections were attributed to lack of labor progress. Arrest of labor 'disorders' are a common indication of primary cesarean section (Barber et al., 2011), and some health professionals may have an overly narrow view of what healthful labor progression constitutes because it is currently altered or terminated after a certain point. 'Normal' parturition then may be perceived as what is commonly experienced, not the full range encountered globally or in the past. Douché and Carryer (2011) similarly describe a 'pathologizing paradox' in which normal bodily performance has emerged as abnormal and cesarean section has surfaced as normal. High rates of induction and the upwards of $20 \%$ of these labors that 'fail' contribute to cesarean section (Talaulikar \& Arulkumaran, 2011), contrary to WHO guidance (2011). In addition to medical factors, the environment can alter the progress of labor (Smith, 2007). However, sensitivity to stress, light, positioning, and other variables are widely unacknowledged (Odent, 2004). Only one participant mentioned the context in which she labored as affecting the need for a cesarean section. Scheduled cesarean section may be influenced by reconstructing negative childbirth experiences to have a positive valence; undergoing what women considered the less ideal birth mode 'turned out to be the best' because circumstances necessitated it. In this study, mothers' stories were not focused on the factors that indirectly influenced the need for the undesired intervention. The hospital environments and women's feelings could have been important factors without them realizing it. Rather than critically examining the interaction among families, health care providers, and the birthing environment, women who underwent cesarean section have reported that the skill of their obstetricians, in a controlled hospital setting, protected them from potential complications (Fenwick et al., 2010).

Besides being conducted for medical conditions, scheduled delivery was viewed by some respondents as a prophylactic to psychological or physical harm. Women described cesarean section as enabling control, predominately through what Namey and Lyerly (2010) describe 
as expressions of self-determinism with regards to perceived choice over delivery events. This stood out in contrast to maternal belief that the process of vaginal childbirth was more unpredictable and potentially traumatic. Our data suggest that women's conceptualizations of the likelihood of achieving their intended childbirth outcomes, and the consequences, influence their feelings on the appropriateness of cesarean section.

Participants spontaneously addressed whether a cesarean section delivery was the "easy" route and defended themselves against the stigma of what they perceived as a social (nonmedical) critique of the operation. When the importance of fetal development in the final stages of gestation (Engle \& Kominiarek, 2008) and the benefits of physical stress on the fetal transition to extrauterine life (Sinha et al., 2011; Jain et al., 2009; Ramachadrappa \& Jain, 2008; Jain \& Eaton, 2006; Lagercrantz \& Slotkin, 1986) are unknown, then it would be difficult to explain why dyads should experience any or especially 'prolonged' labor. A cesarean prior to onset of labor occurs before the infant is ready to be born. Instead of doing their fetuses a favor by sparing them from labor, the consequence of some cesarean section deliveries is unrecognized iatrogenic prematurity.

Mothers who experience a cesarean section after labor may be comforted to know their efforts were biologically healthful. We concur with Lydon-Rochelle et al. (2006) and Pang et al. (2008), that future research could evaluate the effect of postpartum discussion between health care providers and families about birth outcomes and discussion of what could be done to alter the course of events in subsequent deliveries. Improved prenatal information for families, especially those without the means to research the topics independently, may ease the pressure on maternity workers to recommend intervention in conditions of uncertainty. More detailed knowledge, including trade-offs in the context of breech positioning, may also enable families to prenatally solicit appropriate support for labor (see Hodnett et al., 2011) and provide preparation for informed decisions when medical indications do arise.

Our data did not support the assertion that expectant women feel as though they are treated like part of a 'factory production line,' with impersonalized support as suggested by Dykes (2006) and Kitzinger (2006). Instead, some participants specifically praised staff for treating them as individuals. We propose that, like the model of solitary and uninterrupted infant sleep currently dominant in European-American culture (see McKenna \& McDade, 2005, p. 137), the decision for some cesarean sections seem necessary because of a culturallyconstructed cycle of expectations, education, and practice. Figure 1 illustrates the pathways through which high rates of intervention in childbirth become anticipated and routine.

This model of childbirth illustrates what Jordan describes as the "ongoing social process" that results in all participants viewing the current system "as natural order" (1993, p. 152). Redshaw and Hockley (2010) suggest that unsatisfying or upsetting delivery experiences may later masquerade as maternal 'preference' for a cesarean section. Similarly, Waldenström et al. (2006) found that women who had "very negative feelings" about childbirth during their second trimester were more likely to schedule a cesarean section than others. These researchers also found that a greater proportion of the multiparous women who were very negative about the birth had previously undergone unscheduled cesarean section delivery. Scheduling cesarean section in the absence of a current medical condition may be due to women's perception of that approach as the 'lesser of two evils,' not something desired or requested in isolation of past experiences. Women were concerned over the unpredictability of labor and vaginal birth compared to distress regarding the prolonged postpartum pain and limited mobility following cesarean. Our sample did not include women who had vaginal deliveries during the study period, so the findings are not a comparison of the factors that led to the decision for a cesarean section instead of vaginal 
delivery. Future research could investigate how childbirth influences are negotiated among families with different backgrounds, reproductive histories, information, resources, and outcomes.

Cesarean section in a variety of non-medically indicated circumstances may be summarized as méconnaissance or misrecognition (Bourdieu \& Passeron, 1990). Misrecognition is meant as the process of social interactions "not for what they legitimately are but in a form which renders them legitimate in the eyes of the beholder" (p. xxii). Jordan $(1993 ; 1997)$ cites this concept as occurring with the technology-based perspective on human birth, which makes the realization of non-mainstream maternity care "unthinkable" (Davis-Floyd \& Sargent, 1997). Most women in our study portrayed their cesarean section deliveries as everything that they had wanted to avoid, but necessary given their situation. Gamble et al. (2007), Unterscheider et al. (2011), and Klein (2012) recommend reevaluation of obstetrician training to ensure providers have sufficiently opportunity to attend deliveries that provide experience along the physiologic to complicated continuum. Public health campaigns to educate families and research into communication between medical staff and individual mothers may complement this approach. The internationally high rates of operative delivery may be driven by a common misrecognition of the need for cesarean section in various circumstances in which childbirth could proceed differently, in addition to understanding of fetal development and available birth environments.

\section{Conclusions}

The data obtained via semi-structured interviews with mothers and their partners in the days after their cesarean section delivery suggest that undergoing a cesarean section made sense, and this mode of childbirth was not their ideal. Scheduling a cesarean section without a current medical condition was perceived as maximizing maternal and/or infant wellbeing. There was no definitive reason for mothers to think that their outcomes would be different than previously experienced and so these cesarean sections were about cost minimization. The circumstances that 'counted' towards a cesarean section, such as 'failed' labor or prioritization of avoiding previously experienced harm, were influential regardless of the indications' physiological "truth value" (Jordan, 1993, p. 149). Informed choice necessitates families be made aware of the range of possible childbirth experiences and understand the dyadic trade-offs associated with the different pathways. Constraints on achieving vaginal delivery may be partly due to the contexts of birth settings.

Many women who experienced cesarean section delivery described disadvantages, but these were outweighed by belief that the operation minimized potential harm to their infants and/ or themselves. Almost all mothers reported that avoidance of possible harm was better achieved through the controlled application of cesarean section instead of the uncertainty and 'unnecessary' stress of delivering vaginally. The discourse of 'wasted' labor effort may diminish maternal satisfaction with their parturition experiences, undermine confidence in their birthing abilities, and perpetuate the view of technological intervention as necessary for healthful perinatal outcomes. Overall, participants suggested that they would not have undergone the cesarean section if their circumstances had been more conducive to vaginal childbirth. This study suggests that current debate surrounding maternal autonomy in 'elective' cesarean section delivery is misplaced; family health may be better facilitated through increased focus on parturition education and support.

Provision of more specific, physiological information on parturition during pregnancy may minimize the need for cesarean section and enable women more informed decisions when medical indications arise. Participants spontaneously addressed whether a cesarean section delivery was the "easy" route and dismissed what they perceived as a social, not medical, 
critique of the operation. Alteration of the ways in which clinicians and families refer to cesarean sections may promote discussion of the biological rationale for the procedures. Further investigation into culturally constructed perceptions of childbirth and providerfamily discourse may supplement clinical knowledge and public awareness. Additionally, the training of health care providers could be examined to ascertain the degree to which the professionals enable vaginal delivery, or at least labor onset, under a variety of contexts.

\section{Acknowledgments}

This research was funded by The Parkes Foundation. The funding source approved of the study design, but was not involved in data collection, analysis, writing or publication. Kristin P. Tully is currently supported by the National Institutes of Child Health and Human Developmental Training Grant, 5T32HD007376-22. The authors thank Diane Holditch-Davis, Debra Skinner, and Mara Buchbinder for helpful comments on a previous draft of this manuscript.

\section{References}

Alleyne, R. [Accessed July 2012] Too posh to push? Rising caesarean rates driven by middle class. The Telegraph. May 18. 2011 at http://www.telegraph.co.uk/health/healthnews/8518902/Too-poshto-push-Rising-caesarean-rates-driven-by-middle-class.html

Tully KP, Ball HL. Postnatal unit bassinet types when rooming-in after cesarean section birth: Implications for breastfeeding and infant safety. Journal of Human Lactation. 2012; 28(4):495-505. [PubMed: 22914755]

Bassett KL, Iyer N, Kazanjian A. Defensive medicine during hospital obstetrical care: A by-product of the technological age. Social Science \& Medicine. 2000; 51(4):523-537. [PubMed: 10868668]

Béhague DP. Beyond the simple economics of cesarean section birthing: Women's resistance to social inequality. Culture, Medicine and Psychiatry. 2002; 26(4):473-507.

Betrán AP, Merialdi M, Lauer JA, Bing-Shun W, Thomas J, Van Look P, Wagner M. Rates of caesarean section: Analysis of global, regional and national estimates. Paediatric \& Perinatal Epidemiology. 2007; 21(2):98-113. [PubMed: 17302638]

Bolling, K.; Grant, C.; Hamlyn, B.; Thornton, A. Infant feeding survey 2005. The Information Centre; London: 2007. at http://www.ic.nhs.uk/pubs/ifs2005

Bourdieu, P.; Passeron, JC. Reproduction in education, society and culture. Sage Publications; London: 1990. 1977

Bragg F, Cromwell DA, Edozien LC, Gurol-Urganci I, Mahmood TA, Templeton A, van der Meulen $\mathrm{JH}$. Variation in rates of caesarean section among English NHS trusts after accounting for maternal and clinical risk: cross sectional study. British Medical Journal. 2010; 341:c5065. [PubMed: 20926490]

Bryant J, Porter M, Tracy SK, Sullivan EA. Caesarean birth: Consumption, safety, order, and good mothering. Social Science \& Medicine. 2007; 65(6):1192-1201. [PubMed: 17590252]

Cheng, M. [Accessed July 2012] Too posh to push? More C-sections on demand in UK. The Guardian. Nov 4. 2011 at http://www.guardian.co.uk/world/feedarticle/9929873

Danerek M, Marsál K, Cuttini M, Lingman G, Nilstun T, Dukes A-K. Attitudes of midwives in Sweden toward a women's refusal of an emergency cesarean section or a cesarean section on request. Birth. 2011; 38(1):71-79. [PubMed: 21332777]

David S, Fenwick J, Bayes S, Martin T. A qualitative analysis of the content of telephone calls made by women to a dedicated 'Next Birth After Caesarean' antenatal clinic. Women and Birth. 2010; 23(4):166-171. [PubMed: 20739247]

Davis-Floyd, R. The technocratic model of birth. In: Hollis, ST.; Pershing, L.; Young, MJ., editors. Feminist theory in the study of folklore. University of Illinois Press; Champaign, IL: 1993. p. 297-326.

Davis-Floyd R. The technocratic body: American childbirth as cultural expression. Social Science \& Medicine. 1994; 38(8):1125-1140. [PubMed: 8042048] 
Davis-Floyd, RE.; Sargent, CF. Introduction: The anthropology of birth. In: Davis-Floyd, RE.; Sargent, CF., editors. Childbirth and authoritative knowledge: Cross-cultural perspectives. University of California Press; Berkeley: 1997. p. 1-51.

Davis-Floyd, RE.; St. John, G. From doctor to healer: The transformative journey. Rutgers University Press; New Brunswick, NJ: 1998.

De Angelis, S. [Accessed July 2012] Are you too posh to push?. NY Parenting. May. 2011 at http:// www.nyparenting.com/stories/2011/5/sif_health_cesarean_2011_05.html

Declercq E, Cunningham DK, Johnson C, Sakala C. Mothers' reports of postpartum pain associated with vaginal and cesarean deliveries: Results of a national survey. Birth. 2008; 35(1):16-24. [PubMed: 18307483]

Declercq, E.; Sakala, C.; Corry, MP.; Applebaum, S. Listening to mothers II: Report of the second national U.S. survey of women's childbearing experiences. Childbirth Connection; New York: 2006. at http://www.childbirthconnection.org/pdfs/LTMII_report.pdf

Declercq E, Young R, Cabral H, Echer J. Is a rising cesarean delivery rate inevitable? Trends in industrialized countries, 1987 to 2007. Birth. 2011; 38(2):99-104. [PubMed: 21599731]

Douché J, Carryer J. Caesarean section in the absence of need: A pathologising paradox for public health. Nursing Inquiry. 2011; 18(2):143-153. [PubMed: 21564395]

Dykes, F. Breastfeeding in hospital: Mothers, midwives and the production line. Routledge; London: 2006.

Engle WA, Kominiarek MA. Late preterm infants, early term infants, and timing of elective deliveries. Clinics in Perinatology. 2008; 35(2):325-341. [PubMed: 18456072]

Fenwick J, Staff L, Gamble J, Creedy DK, Bayes S. Why do women request caesarean section in a normal, healthy first pregnancy? Midwifery. 2010; 26(4):394-400. [PubMed: 19117644]

Fisher C, Hauck Y, Fenwick J. How social context impacts on women's fears of childbirth: A Western Australian example. Social Science \& Medicine. 2006; 63(1):64-75. [PubMed: 16476516]

Gamble J, Creedy DK, McCourt C, Weaver J, Beake S. A critique of the literature on women's request for cesarean section. Birth. 2007; 34(4):331-340. [PubMed: 18021149]

Getahun D, Strickland D, Lawrence JM, Fassett MJ, Koebnick C, Jacobsen SJ. Racial and ethnic disparities in the trends in primary cesarean delivery based on indications. American Journal of Obstetrics \& Gynecology. 2009; 201(4):422e1-7. [PubMed: 19788975]

Ginsburg F, Rapp R. The politics of reproduction. Annual Review of Anthropology. 1991; 20:311341.

Hamilton, BE.; Martin, JA.; Ventura, SJ. Births: Preliminary data for 2009. Centers for Disease Control and Prevention National Vital Statistics System; Washington, DC: 2010. at http:// www.cdc.gov/nchs/data/nvsr/nvsr59/nvsr59_03.pdf

Hannah ME, Hannah WJ, Hewson SA, Hodnett ED, Saigal S, Willan AR. Planned caesarean section versus planned vaginal birth for breech presentation at term: A randomised multicentre trial. The Lancet. 2000; 356(9239):1375-1383.

Hodnett ED, Gates S, Hofmeyr GJ, Sakala C, Weston J. Continuous support for women during childbirth. Cochrane Database of Systematic Reviews. 2011; (2) Art. No.: CD003766. DOI: 10.1002/14651858.CD003766.pub3.

Jain NJ, Kruse LK, Demissie K, Khandelwal M. Impact of mode of delivery on neonatal complications: Trends between 1997 and 2005. The Journal of Maternal, Fetal \& Neonatal Medicine. 2009; 22(6):491-500.

Jain L, Eaton DC. Physiology of fetal lung fluid clearance and the effect of labor. Seminars in Perinatology. 2006; 30(1):34-43. [PubMed: 16549212]

Jordan, B. Birth in four cultures: A crosscultural investigation of childbirth in Yucatan, Holland, Sweden, and the United States. 4th ed.. Waveland Press Incorporated; Prospect Heights, IL: 1993.

Jordan, B. Authoritative knowledge and its construction. In: Davis-Floyd, RE.; Sargent, CF., editors. Childbirth and authoritative knowledge: Cross-cultural perspectives. University of California Press; Berkeley: 1997. p. 55-79.

Kaimal AJ, Kuppermann M. Understanding risk, patient and provider preferences, and obstetrical decision making: Approach to delivery after cesarean. Seminars in Perinatology. 2010; 34(5):331336. [PubMed: 20869549] 
Karlström A, Nystedt A, Hildingsson I. A comparative study of the experience of childbirth between women who preferred and had a caesarean section and women who preferred and had a vaginal birth. Sexual \& Reproductive Healthcare. 2011a; 2(3):93-99. [PubMed: 21742287]

Karlström A, Nystedt A, Johansson M, Hildingsson I. Behind the myth - Few women prefer caesarean section in the absence of medical or obstetrical factors. Midwifery. 2011b; 27(5):620-627. [PubMed: 20630634]

Kingdon C, Neilson J, Singleton V, Gyte G, Hart A, Gabbay M, Lavender T. Choice and birth method: Mixed-method study of caesarean deliver for maternal request. BJOG: An International Journal of Obstetrics and Gynaecology. 2009; 116(7):886-895. [PubMed: 19385961]

Kitzinger, S. Birth crisis. Routledge; London: 2006.

Kitzinger S, Green JM, Chalmers B, Keirse M, Lindstrom K, Hemminki E. Why do women go along with this stuff? Birth. 2006; 33(2):154-158. [PubMed: 16732782]

Klein MC. Cesarean section on maternal request: A societal and professional failure and symptom of a much larger problem. Birth. 2012; 39(4):305-310. [PubMed: 23281950]

Klein MC, Sakala C, Simkin P, Davis-Floyd R, Rooks JP, Pincus J. Why do women go along with this stuff? Birth. 2006; 33(3):245-250. [PubMed: 16948725]

Kukla R, Kuppermann M, Little M, Lyerly AD, Mitchell LM, Armstrong EM, Harris L. Finding autonomy in birth. Bioethics. 2009; 23(1):1-8. [PubMed: 19076937]

Lagercrantz H, Slotkin TA. The "stress" of being born. Scientific American. Apr; 1986 254(4):100107. [PubMed: 3961465]

Lawrence, J. [Accessed July 2012] Too posh to push? Chelsea has the highest caesarian rate in England. The Independent. Dec 2. 2011 at http://www.independent.co.uk/life-style/health-andfamilies/health-news/too-posh-to-push-chelsea-has-the-highest-caesarian-rate-inengland-6270742.html

Leone T, Padmadas SS, Matthews Z. Community factors affecting rising caesarean section rates in developing countries: An analysis of six countries. Social Science \& Medicine. 2008; 67(8):12361246. [PubMed: 18657345]

Lydon-Rochelle MT, Gardella C, Cárdenas V, Easterling T. Repeat cesarean delivery: What indications are recorded in the medical chart? Birth. 2006; 33(1):4-11. [PubMed: 16499526]

Mancuso MS, Rouse DJ. Cesarean delivery for abnormal labor. Clinics in Perinatology. 2008; 35(3): 479-490. [PubMed: 18952016]

Martin, E. The woman in the body: A cultural analysis of reproduction. Beacon Press; Boston: 1991.

McKenna JJ, McDade T. Why babies should never sleep alone: A review of the co-sleeping controversy in relation to SIDS, bedsharing and breastfeeding. Paediatric Respiratory Reviews. 2005; 6(2):134-152. [PubMed: 15911459]

Merenstein DJ, Gatti ME, Mays DM. The association of mode of delivery and common childhood illnesses. Clinical Pediatrics. 2011; 50(11):1024-1030. [PubMed: 21652596]

Menacker F, Declercq E, Macdorman MF. Cesarean delivery: Background, trends, and epidemiology. Seminars in Perinatology. 2006; 30(5):235-241. [PubMed: 17011392]

Menacker, F.; Hamilton, BE. Recent trends in cesarean delivery in the United States. National Center for Health Statistics; Hyattsville, MD: 2010. NCHS Data Briefat http://www.cdc.gov/nchs/data/ databriefs/db35.pdf

Munro S, Kornelsen J, Hutton E. Decision making in patient-initiated elective cesarean delivery: The influence of birth stories. Journal of Midwifery \& Women's Health. 2009; 54(5):373-379.

Namey EE, Lyerly AD. The meaning of "control" for childbearing women in the US. Social Science \& Medicine. 2010; 71(4):769-776. [PubMed: 20579792]

National Institute for Health and Clinical Excellence. [Accessed December 2011] Caesarean section. NICE clinical guideline 132. 2011. at http://www.nice.org.uk/nicemedia/live/ 13620/57163/57163.pdf

Pang MW, Leung TN, Lau TK, Chung TKH. Impact of first childbirth on changes in women's preference for mode of delivery: Follow-up of a longitudinal observational study. Birth. 2008; 35(2):121-128. [PubMed: 18507583] 
Potter JE, Hopkins K, Faúndes A, Perpétuo I. Women's autonomy and scheduled cesarean sections in Brazil: A cautionary tale. Birth. 2008; 35(1):33-40. [PubMed: 18307486]

Ramachadrappa A, Jain L. Elective cesarean section: Its impact on neonatal respiratory outcome. Clinics in Perinatology. 2008; 35(2):373-393. [PubMed: 18456075]

Rosenthal L, Lobel M. Explaining racial disparities in adverse birth outcomes: Unique sources of stress for Black American women. Social Science \& Medicine. 2011; 72(6):977-983. [PubMed: 21345565]

Selo-Ojeme D, Abulhassan N, Mandal R, Tirlapur S, Selo-Ojeme U. Preferred and actual delivery mode after a cesarean in London, UK. International Journal of Gynecology and Obstetrics. 2008; 102(2):156-159. [PubMed: 18436222]

Sharma PS, Eden KB, Guise J-M, Jimison HB, Dolan JG. Subjective risk vs. objective risk can lead to different post-cesarean birth decisions based on multiattribute modeling. Journal of Clinical Epidemiology. 2011; 64(1):67-78. [PubMed: 20558035]

Silver RM. Delivery after previous cesarean: Long-term maternal outcomes. Seminars in Perinatology. 2010; 34(4):258-266. [PubMed: 20654776]

Sinha A, Bewley A, McIntosh T. Myth: Babies would choose prelabour caesarean section. Seminars in Fetal \& Neonatal Medicine. 2011; 16(5):247-253. [PubMed: 21570370]

Solheim KN, Easakoff TF, Little SE, Cheng YW, Sparks TN, Caughey AB. The effect of cesarean delivery rates on the future incidence of placenta previa, placenta accreta, and maternal mortality. The Journal of Maternal-Fetal and Neonatal Medicine. 2011; 24(11):1341-1346.

Song S, Downie A, Gibson S, Kloberdanz K, McDowell J. Medicine: Too posh to push? Time Magazine. Apr 19.2004 at http://www.time.com/time/magazine/article/0,9171,993857,00.html.

Stavrou EP, Ford JB, Shand AW, Morris JM, Roberts CL. Epidemiology and trends for caesarean section births in New South Wales, Australia: A population-based study. BMC Pregnancy and Childbirth. 2011; 11:8. [PubMed: 21251270]

Stoll K, Fairbrother N, Carty E, Jordan N, Miceli C, Vostrcil Y, Willihnganz L. "It's all the rage these days:" University students' attitudes toward vaginal and cesarean birth. Birth. 2009; 36(2):133140. [PubMed: 19489807]

Talaulikar VS, Arulkumaran S. Failed induction of labor: Strategies to improve the success rates. Obstetrical \& Gynecological Survey. 2011; 66(11):717-728. [PubMed: 22186603]

Thomas, J.; Paranjothy, S. Royal College of Obstetricians and Gynaecologists Clinical Effectiveness Support Unit. National sentinel caesarean section audit report. RCOG Press; London: 2001. at http://www.rcog.org.uk/files/rcog-corp/uploaded-files/nscs_audit.pdf

Unterscheider J, McMenamin M, Cullinane F. Rising rates of caesarean deliveries at full cervical dilation: A concerning trend. European Journal of Obstetrics \& Gynecology and Reproductive Biology. 2011; 157(2):141-4. [PubMed: 21470764]

Waldenström U, Hildigsson I, Ryding EL. Antenatal fear of childbirth and its association with subsequent caesarean section and experience of childbirth. BJOG: An International Journal of Obstetrics \& Gynaecology. 2006; 113(6):638-646. [PubMed: 16709206]

Walker R, Turnbull D, Wilkinson C. Increasing cesarean section rates: Exploring the role of culture in an Australian community. Birth. 2004; 31(2):117-124. [PubMed: 15153131]

Weaver JJ, Statham H, Richards M. Are there "unnecessary" cesarean sections? Perceptions of women and obstetricians about cesarean sections for nonclinical indications. Birth. 2007; 34(1):32-41. [PubMed: 17324176]

Wendland CL. The vanishing mother: Cesarean section and "evidence-based obstetrics". Medical Anthropology Quarterly. 2007; 21(2):218-233. [PubMed: 17601085]

Wibe T, Helles $\varnothing$ R, Slaughter L, Ekstedt M. Lay people's experiences with reading their medical record. Social Science \& Medicine. 2011; 72(9):1570-1573. [PubMed: 21497971]

Wilkinson, S. Focus group research. In: Silverman, D., editor. Qualitative research: Theory, method and practice. 2nd ed.. Sage Publications; London: 2004. p. 177-199.

Wittmann-Price RA, Fliszar R, Bhattacharya A. Elective cesarean births: Are women making emancipated decisions. Applied Nursing Research. 2009; 24(3):147-152. [PubMed: 21777789]

World Health Organization. at http://whqlibdoc.who.int/publications/2009/9789241547734_eng.pdf. [Accessed May 2011] Monitoring emergency obstetric care: A Handbook. 2009. http:// 
whqlibdoc.who.int/publications/2009/9789241547734_eng.pdfhttp://whqlibdoc.who.int/ publications/2009/9789241547734_eng.pdf

World Health Organization. [Accessed December 2011] WHO recommendations for induction of labor. 2011. at http://whqlibdoc.who.int/publications/2011/9789241501156_eng.pdf

Zhang J, Troendle J, Reddy AM, Laughon K, Branch DW, Burkman R, Landy HJ, Hibbard JU, Haberman S, Ramirez MM, Bailit JL, Hoffman MK, Gregory KD, Hatjis CG, van Veldhuisen P. Contemporary cesarean delivery practice in the United States. American Journal of Obstetrics and Gynecology. 2010; 203(4):326.e1-326.e10. [PubMed: 20708166] 


\section{Research highlights}

- In contrast to 'maternal request', most women felt their context necessitated cesarean.

- Cesarean as 'emergency' or 'elective' was largely unreflective of maternal experience.

- Mothers viewed labor prior to cesarean as wasted effort.

- Misrecognition of cesarean need arises from perceptions of the value and risks of labor.

- Medical training may need revision to support physiologic, vaginal childbirth. 


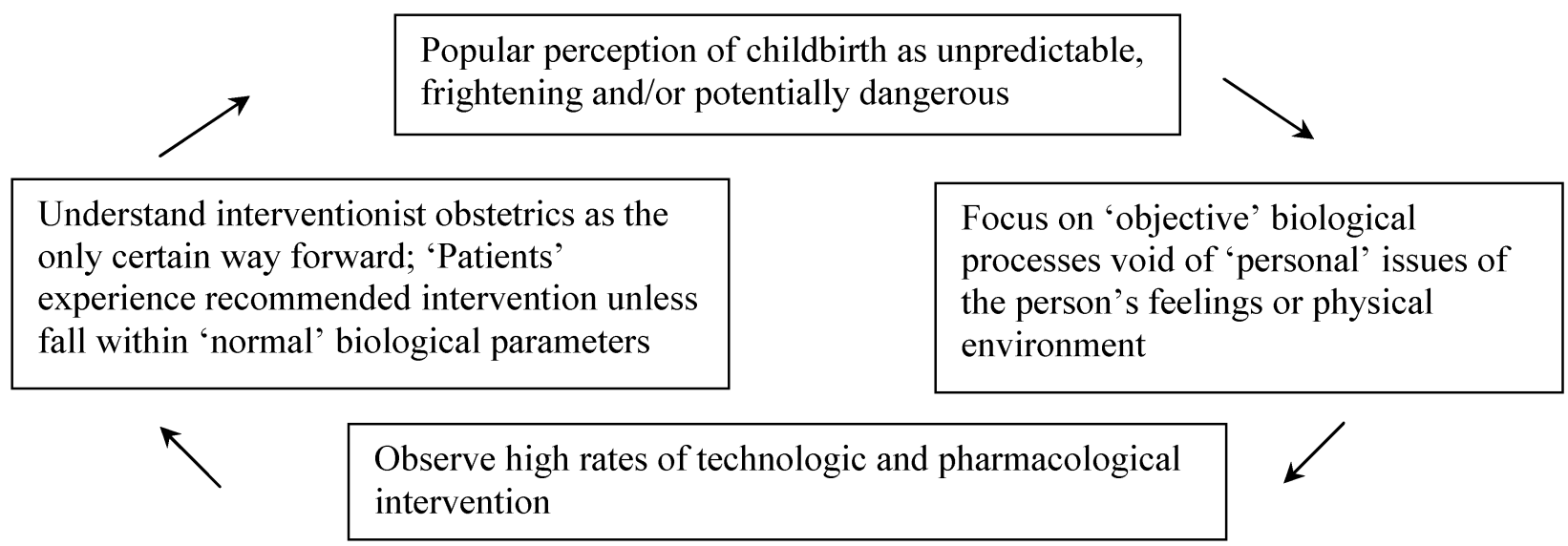

Figure 1. A cycle of childbirth intervention as 'normal' and best practice 
Table 1

\section{Participant demographics}

\begin{tabular}{|l|c|c|}
\hline Mothers, N=115 & Phase 1, $\boldsymbol{n = 7 5}$ & Phase 2, $\boldsymbol{n = 4 0}$ \\
\hline & \multicolumn{2}{|c|}{ Median (range) or \% (n) } \\
\hline - Parity & $0(0-3)$ & $0(0-6)$ \\
\hline - Previously had a cesarean section & $29.3(22 / 75)$ & $55.0(22 / 40)$ \\
\hline - Age in years & $29(18-41)$ & $34(23-41)$ \\
\hline - Living with partner & $85.3(64 / 75)$ & $97.5(39 / 40)$ \\
\hline - Education completed ${ }^{*}$ & $\begin{array}{c}\text { Some university } \\
\text { (no GCSEs - Doctorate) }\end{array}$ & $\begin{array}{c}\text { University degree } \\
\text { (no GCSEs - Doctorate) }\end{array}$ \\
\hline - White European & $85.3(64 / 75)$ & $85.0(34 / 40)$ \\
\hline Infants, N=122 & Phase $1, n=82$ & Phase 2, $n=40$ \\
\hline - Singleton & $90.6(68 / 75)$ & $100.0(40 / 40)$ \\
\hline - Female & $51.2(42 / 82)$ & $65.0(26 / 40)$ \\
\hline - Gestational age in weeks + days & $39+3(30+3-42+6)$ & $39+1(37+4-41+1)$ \\
\hline - Apgar score at 5 minutes & $9(3-10)$ & $9(9-10)$ \\
\hline
\end{tabular}

GCSE stands for General Certificate of Secondary Education. These exams are taken in the UK at the age of 16 years at the end of their compulsory high school education. 
Table 2

\section{Cesarean section delivery subgroups}

\begin{tabular}{|c|c|c|c|}
\hline \multicolumn{2}{|c|}{$\begin{array}{l}\text { Did not schedule cesarean section delivery } \\
\text { Phase } 1 n=48\end{array}$} & \multicolumn{2}{|c|}{$\begin{array}{c}\text { Scheduled cesarean section delivery } \\
\text { Phase } 1 \mathrm{n}=\mathbf{2 7} \\
\text { Phase } 2 n=\mathbf{4 0} \\
\end{array}$} \\
\hline $\begin{array}{l}\text { Conducted without a } \\
\text { medical condition } \\
\text { Phase } 1 n=16,33.3 \%\end{array}$ & $\begin{array}{l}\text { Conducted for a medical } \\
\text { condition } \\
\text { Phase } 1 n=32,66.7 \%\end{array}$ & $\begin{array}{l}\text { Conducted without a } \\
\text { medical condition } \\
\text { Phase } 1 n=15,55.6 \% \\
\text { Phase } 2 n=29,72.5 \%\end{array}$ & $\begin{array}{l}\text { Conducted for a medical } \\
\text { condition } \\
\text { Phase } 1 n=12,44.4 \% \\
\text { Phase } 2 n=11,27.5 \%\end{array}$ \\
\hline \multicolumn{2}{|c|}{ Indications for unscheduled cesarean section: } & \multicolumn{2}{|c|}{ Indications for scheduled cesarean section: } \\
\hline \multirow[t]{3}{*}{$\begin{array}{l}\text { Non-progressive labor, } \\
n=16,33.3 \%\end{array}$} & $\begin{array}{l}\text { Emergency conditions, } \\
n=8,16.7 \% \\
3 \text { preeclampsia } \\
2 \text { umbilical } \\
\text { cord prolapse } \\
1 \text { placenta previa } \\
1 \text { placental abruption } \\
1 \text { abnormal bleeding }\end{array}$ & $\begin{array}{l}\text { Repeat cesarean section } \\
\text { Phase } 1 n=12,44.4 \% \\
\text { Phase } 2 n=20,50.0 \%\end{array}$ & $\begin{array}{l}\text { Breech fetal positioning } \\
\text { Phase } 1 n=6,22.2 \% \\
\text { Phase } 2 n=7,17.5 \%\end{array}$ \\
\hline & $\begin{array}{l}\text { Indications of fetal } \\
\text { distress, } n=18,37.5 \% \\
\quad 17 \text { fetal heartbeat } \\
\quad 1 \text { fetal oxygen level }\end{array}$ & $\begin{array}{l}\text { Previous complications } \\
\text { with vaginal delivery } \\
\text { Phase } 1 n=2,7.4 \% \\
\text { Phase } 2 n=9,22.5 \%\end{array}$ & \multirow{2}{*}{$\begin{array}{c}\text { Maternal conditions } \\
\text { Phase } 1 n=6,22.2 \% \\
\text { Phase } 2 n=4,36.4 \% \\
3 \text { placenta previa } \\
2 \text { uterine fibroids } \\
1 \text { ovarian cyst } \\
1 \text { cystic fibrosis } \\
1 \text { high blood pressure } \\
1 \text { blood clotting } \\
\text { disorder } \\
1 \text { neurostimulator }\end{array}$} \\
\hline & $\begin{array}{l}\text { Suboptimal fetal } \\
\text { positioning, } n=6,12.5 \% \\
5 \text { breech presentation } \\
1 \text { brow presentation }\end{array}$ & $\begin{array}{l}\text { Maternal 'request' } \\
\text { Phase } 1 n=1,3.7 \%\end{array}$ & \\
\hline
\end{tabular}

